Jurnal Mandala Pharmacon Indonesia, Vol 4.No.1 Juni 2018

Avaiable online at www.jurnal-pharmaconmw.com/jmpi

$p$-ISSN : 2442-6032

e-ISSN : 2598-9979

\title{
Formulasi Sampo Antiketombe Dari Ekstrak Kubis (Brassica oleracea Var. Capitata L.) Kombinasi Ekstrak Daun Pandan Wangi (Pandanus amaryllifolius Roxb)
}

Eny Nurhikma*, Dewi Antari, Selfyana Austin Tee

Laboratorium Farmasetika, Akademi Farmasi Bina Husada Kendari

\begin{abstract}
ABSTRAK
Sampo ekstrak kubis kombinasi daun pandan wangi adalah sediaan kosmetik yang dibuat dari bahan dasar ekstrak kubis dan daun pandan wangi serta penambahan bahan lain yang dapat digunakan pada kulit kepala tanpa menimbulkan iritas. Ekstrak kubis dan daun pandan wangi memiliki senyawa yang berkhasiat menghambat pertumbuhan ketombe pada kulit kepala, penelitian ini bertujuan untuk membuat sediaan sampo antiketombe dari ekstrak kubis kombinasi daun pandan wangi yang dapat memenuhi uji evaluasi fisik sediaan. Penelitian ini dilakukan

yang dihasilkan dari ketiga formula yaitu formula A, formula B dan formula C berwarna hijau gelap disebabkan oleh zat aktif yang digunakan yaitu daun pandan wangi, aroma yang dihasilkan adalah aroma dari penambahan pewangi yang digunakan dalam sediaan, pewangi yang digunakan yaitu minyak mawar serta bentuk dari sediaan yaitu kental. Pada uji pH ketiga formulasi telah memenuhi syarat mutu $\mathrm{pH}$ kulit kepala yaitu 4,5 6,5. Formula yang dihasilkan menghasilkan tinggi busa yang baik. Sediaan sampo yang dibuat dari ketiga formula homogen dan kental .
\end{abstract} secara eksperimental dengan beberapa evaluasi fisik sediaan diantaranya yaitu uji organoleptik, berdasarkan warna, bentuk dan aroma sediaan, uji $\mathrm{pH}$, uji tinggi busa, uji homogenitas, dan uji viskositas. Hasil penelitian menunjukan formula sampo antiketombe ekstrak kubis dan daun pandan wangi hasilnya menunjukka bahwa uji evaluasi fisik sediaan sampo antiketombe ekstrak kubis kombinasi daun panan wangi memenuhi syarat secara fisik, pada uji organoleptik warna

\section{PENDAHULUAN}

Rambut merupakan tambahan pada

kulit kepala yang memberikan

kehangatan, perlindungan dan keindahan.

Rambut juga terdapat diseluruh tubuh,

kecuali telapak tangan, telapak kaki dan

bibir. Jenis-jenis kosmetik yang digunakan
Kata Kunci : Sampo, Ekstrak Kubis, Daun Pandan Wangi

Penulis Korespondensi:

Eny Nurhikma

Laboratorium Farmasetika, Akademi Farmasi Bina Husada Kendari

E-mail : eyninurhikma@gmail.com

pada kulit kepala yaitu dalam bentuk sediaan hair tonic, gel penumbuh rambut, vitamin rambut, pelembab rambut, masker rambut dan sampo (Permenkes, 2010).

Sampo merupakan produk yang digunakan untuk menjaga kebersihan dan kesehatan rambut. Sehingga pemilihan 
sampo yang tepat akan sangat berpengaruh pada pertumbuhan rambut. Rambut yang berketombe hingga kini masih merupakan gangguan yang dapat menghambat kenyamanan beraktivitas. Dilaporkan bahwa hampir $60 \%$ orang bermasalah dengan ketombe. Ketombe adalah suatu gangguan berupa pengelupasan kulit mati secara berlebihan di kulit kepala, kadang disertai pula dengan pruritus (gatal-gatal) dan peradangan. Penyebab ketombe dapat berupa sekresi kelenjar keringat yang berlebihan atau adanya peranan mikroorganisme di kulit kepala yang menghasilkan suatu metabolit yang dapat menginduksi terbentuknya ketombe di kulit kepala Mikroorganisme yang diduga sebagai penyebab utama ketombe adalah Pityrosporum ovale (P.Ovale) atau Malassezia furfur. Jamur ini sebenarnya merupakan flora normal di kulit kepala, namun pada kondisi rambut dengan kelenjar minyak berlebih, jamur ini dapat tumbuh dengan subur (Ratnawulan, 2009).

\section{METODOLOGI}

\section{Alat dan Bahan}

Alat yang digunakan: batang pengaduk, lumpang dan alu, gelas kimia, gelas ukur, sendok tanduk, timbangan digital, toples kaca, wadah sampo.

Bahan yang digunakan: Aquadest, ekstrak daun pandan wangi, ekstrak kubis, sls cair, HPMC, gliserol, metil Paraben, propil paraben, pewangi Roman Swiss.

\section{Prosedur Penelitian}

\section{Pembuatan Sediaan Sampo}

Disiapkan alat dan bahan yang akan digunakan, ditimbang semua bahan yang akan digunakan, dibuat muchilago HPMC pada suhu $60^{\circ} \mathrm{C}$ dengan cara: Dipanaskan $30 \mathrm{~mL}$ aquadest sampai mendidih kemudian masukkan metil paraben aduk hingga larut, dan masukkan 20 bagian air panas dalam lumpang, 
dengan cara ditaburkan di atasnya dan didiamkan selama 15 menit, setelah 15 menit gerus kuat hingga terbentuk mucilago. Dimasukkan ekstrak etanol kubis dan daun pandan wangi ke dalam lumpang yang berisi mucilago HPMC digerus. Dimasukan gliserol, masukkan propil paraben dalam cawan porselin aduk hingga homogen, kemudian dimasukkan ke dalam lumpang, gerus hingga homogen, dimasukkan SLS cair sedikit demi sedikit gerus pelan agar tidak terbentuk busa, dimasukkan roman swis ke dalam lumpang secukupnya aduk hingga homogen. Dimasukkan ke dalam wadah yang telah dikalibrasi dan diberi etiket.

\section{Evaluasi Fisik Sediaan}

Evaluasi fisik sediaan dilakukan dengan melakukan pengamatan organoleptik, pengukuran $\mathrm{pH}$, pengamatan homogenitas, pengukuran tinggi busa, dan pengukuran viskositas sediaan sampo.

\section{HASIL DAN PEMBAHASAN}

\section{Penyiapan dan Ekstraksi Kubis dan}

\section{Daun Pandan Wangi}

Telah dilakukan penelitian formulasi sampo antiketombe ekstrak kubis kombinasi ekstrak daun pandan wangi.Penyiapan kubis dan daun pandan wangi yang dibutuhkan dicuci bersih dengan air mengalir sampai semua kotorannya hilang. Selanjutnya dirajang agar permukaan kubis dan daun pandan wangi semakin luas sehingga mempercepat proses pengeringan. Kemudian dikeringkan tanpa terkena sinar matahari langsung. Pengeringan bertujuan untuk menurunkan kadar air, sehingga dapat mencegah terjadinya reaksi enzimatik dan mencegah terjadinya penurunan mutu dari kubis dan daun pandan wangi. Saat pengeringan kedua sampel ditutup dengan kain hitam agar terhindar dari sinar matahari langsung yang dapat menimbulkan kerusakan pada 
kandungan kimia dari kubis dan daun pandan wangi yang di keringkan.

Ekstraksi kubis dan daun pandan wangi dilakukan menggunakan metode maserasi. Proses ekstraksi dilakukan selama tiga sampai lima hari pada temperatur kamar dan terlindung dari cahaya dengan sesekali pengadukan untuk mencegah kejenuhan. Metode maserasi dipilih karena alat yang digunakan sederhana dan dalam prosesnya tanpa mengalami pemanasan sehingga dapat menghindari rusaknya senyawa-senyawa yang bersifat termolabil (Ratnawulan, 2009). Larutan penyari yang digunakan dalam penelitian ini adalah etanol. Ekstrak cair yang diperoleh, kemudian diuapkan hingga kental menggunakan Rotavapor pada suhu $60^{\circ} \mathrm{C}$. Ekstrak kental diperoleh digunakan untuk pembuatan sampo dengan konsentrasi kubis $15 \%$ dan konsentrasi daun pandan wangi $10 \%, 15 \%$, dan $20 \%$.

\section{Formulasi Sampo Ekstrak Kubis} Kombinasi Daun Pandan Wangi

Pembuatan sampo terdiri dari zat aktif yaitu ekstrak kubis dan daun pandan wangi. Kubis yang mengandung senyawa tanin, flavonoid, monoterpenoid, seskuiterpenoid, triterpenoid dan saponin senyawa-senyawa tersebut akan memberikan antifitas antijamur terhadap M. Furfur yang terdapat pada kulit kepala. Daun pandan wangi mempunyai kandungan senyawa kimia alkaloida, saponin, flavonoida, tanin, polifenol,dan zat warna yang mampu menghambat pertumbuhan campuran bakteri yang diisolasi dari kulit kepala. Untuk mendapatkan sediaan yang baik, selain zat aktif dalam penelitian ini menggunakan komponen tambahan yaitu SLS cair $10 \%$, metil paraben $0,18 \%$, propil paraben 0,02 $\%$, HPMC $3 \%$, gliserol $5 \%$, pengharum secukupnya, dan aquadest ad $100 \mathrm{~mL}$. SLS (sodium lauryl sulfat) cair.Pada penelitian ini, dibuat formulasi dengan konsentrasi 
ekstrak yang berbeda namun organoleptik, uji $\mathrm{pH}$, uji tinggi busa dan uji pembawanya sama yang bertujuan untuk homogenitas dan uji viskositas. mengetahui pengaruh dari hasil evaluasi fisik sediaan yang meliputi uji

Tabel 1. Hasil evaluasi fisik

\begin{tabular}{cccccc}
\hline \multirow{2}{*}{ Formula } & \multicolumn{5}{c}{ Evaluasi Fisik } \\
\cline { 2 - 6 } A & Organoleptik & $\mathrm{pH}$ & Homogenitas & Tinggi Busa & Viskositas \\
\hline & $\begin{array}{c}\text { Hijau gelap, } \\
\text { kental, aroma } \\
\text { khas mawar }\end{array}$ & 5 & homogen & 7,25 & 105 \\
B & $\begin{array}{c}\text { hijau gelap, } \\
\text { kental, aroma } \\
\text { khas mawar }\end{array}$ & 5 & homogen & 7,25 & 102,5 \\
\hline C & $\begin{array}{l}\text { hijau gelap, } \\
\text { kental, aroma } \\
\text { khas mawar }\end{array}$ & 5 & homogen & 7,25 & 110 \\
\hline D & $\begin{array}{c}\text { bening, kental, } \\
\text { aroma khas } \\
\text { mawar }\end{array}$ & 5 & homogen & 7,25 & 120 \\
\hline
\end{tabular}

\section{Evaluasi Fisik Sediaan Sampo Ekstrak}

\section{Kubis Kombinasi Daun Pandan Wangi}

Evaluasi fisik sediaan dilakukan dengan melakukan pengamatan organoleptik, pengukuran $\quad \mathrm{pH}, \quad$ pengamatan homogenitas, pengukuran tinggi busa dan viskositas. Berdasarkan hasil pengujian pada Tabel 1, hasil uji evaluasi fsik menunjukkan tidak adanya perbedaan aroma, bentuk dan warna pada formula A, formula B, formula C dan blanko.
Berdasarkan hasil pengukuran $\mathrm{pH}$, diperoleh nilai $\mathrm{pH}$ suatu sediaan sampo pada keempat formula masih menunjukkan $\mathrm{pH}$ yang sesui untuk $\mathrm{pH}$ kulit kepala yaitu berkisar antara 5,0-9,0 sesui dengan SNI 06-4085-1996 untuk sediaan sampo. Berdasarkan hasil pengamatan homogenitas diperoleh hasil sediaan sampo dari keempat formula memiliki homogen yang stabil. Diperoleh pengukuran tinggi busa dari keempat formula yaitu $7,25 \mathrm{~cm}$ tidak ada perbedaan 
tinggi busa dari keempat formula.

Berdasarkan pengamatan viskositas

formula A didapatkan nilai sebangak 105,

formula B sebanyak 102,5, formula C nilai

sebanyak 110 pada formula D disini

menggunakan salah satu merek yang

beredar dipasaran memiliki nilai viskositas

120.

\section{KESIMPULAN}

Berdasarkan dari hasil penelitian yang dilakukan mengenai formulasi sediaan sampo ekstrak kubis kombinasi daun pandan wangi dapat diperoleh kesimpulan sebagai berikut : Ekstrak kubis kombinasi ekstrak daun pandan wangi dapat dibuat dalam sediaan sampo, dan hasil sediaan sampo yang memenuhi syarat uji evaluasi fisik sediaan (uji organoleptik, uji homogenitas, uji $\mathrm{pH}$, uji tinggi busa, dan uji viskositas).

\section{DAFTAR PUSTAKA}

Ambarwati, Tanti, A. Retno, S.2016, Uji Aktivitas Daun Pandan Wangi (Pandanus Amaryllfolius Roxb.) Sebagai Antibakteri
Departemen Kesehatan RI, 1995, Farmakope Indonesia Edisi $I V$,Departemen Kesehatan RI, Jakarta.

Departemen Kesehatan RI, 1979, Farmakope Indonesia Edisi III,

Departemen Kesehatan RI, Jakarta.

Imas, Maesaroh. 2016. Formulasi Sediaan

Sampo Jelly Antiketombe Dari Ekstrak Kangkung (Ipomoea aquatica Forrsk). Kuningan.

Kibbe, A.H. 2000. Handbook of Pharmaceutical Exicipients, Third edition. American

Pharmaceutical Press. USA

Lia Suryati, dkk. Formulasi Sampo Ekstrak

Daun Teh Hijau (Camellia sinensis var. Assamica). Bandung

Universitas AL Gifari

Nuriyani, Sri. 2014. Analisis Pengaruh Iklan Citra Merek dan Harga Terhadap Keputusan

Pembelian Sampo Sunsilk Di Semarang:

Fakultas Ekonomika dan Bisnis

Universitas Diponegoro Semarang

Pertiwi M, dkk. 20014. Optimalisasi Konsentrasi Ekstrak Saponin Daun Petai Cina (Leucaena leucocephala (Lam.) De Wit.) Sebagai Agensia Pembusa Alami Sampo. Surakaarta : Program Studi Pendidikan Kimia Jurusan PMPA FKIP UNS. 
Ratnawulan, M., Dewi, R. dan Sri, A.2009,' Pengembangan Ekstrak Etanol Kubis (Brassica oleracea var. Capitata L.) Asal Kabupaten

Bandung Barat dalam Bentuk Sampo Antiketombe terhadap Jamur Malassezia furfur'.

Bandung: Fakultas Farmasi

Universitas Padjadjaran

November.

Rowe, Raymond C, dkk. 2009. Handbook of Pharmaceutical Exicipienth(6th). London : Pharmaceutical Press.

Rusmiati, Dewi. 2007. Pemanfaatan Kubis (Brassica Oleracea Var. capitata alba) Sebagai Kandidat Antikeputihan. Bandung: Fakultas Farmasi Universitas Padjadjaran Bandung.

Sa'bania, Retmawati. 2014. Penerapan Model Pembelajaran Kooperatif Tipe Jigsaw Pada
Kompetensi Dasar dan Kelainan Rambut Untuk Meningkatkan Hasil Belajar Siswa SMK Negeri 8 Surabaya.

Tania, Inggrid. 2012. Formulasi Uji Stabilitas Fisik dan Uji Manfaat Shampoo Mikroemulsi Minyak Biji Mimba Pada Ketombe Derajat Ringan-Sedang. Fakultas Matematika Dan Pengetahuan Alam Program Studi Magister Herbal Depok.

Tranggono dan Latifah. 2007. Pengantar Kosmetologi. Editor: Joshita Djajadisastra. Jakarta: PT. Gramedia Pustaka Utama.

Wardiyah, Sry. 2015. Perbandingan Sifat Fisik Sediaan Krim, Gel, dan Salep Menggunakan Etil P-Metoksisinamat dari Ekstrak Rimpang Kencur (Kaempferia galanga Linn.) 